Journal of Advanced Research in Fluid Mechanics and Thermal Sciences

\title{
Numerical Analysis of a Mobile Leakage-Detection System for a Water Pipeline Network
}

\author{
Balbir Singh ${ }^{1,2}$, Usman Ikhtiar ${ }^{3,4}$, Mohamad Firzan $^{3}$, Dong Huizhen ${ }^{3}$, Kamarul Arifin Ahmad $^{1,5, *}$ \\ Department of Aerospace Engineering, Faculty of Engineering, Universiti Putra Malaysia, Serdang, 43400, Malaysia \\ 2 Department of Aeronautical and Automobile Engineering, Manipal Institute of Technology, Manipal Academy of Higher Education, Manipal \\ 576104, Karnataka, India \\ 3 Department of Mechanical and Manufacturing Engineering, Faculty of Engineering, Universiti Putra Malaysia, Serdang, 43400, Malaysia \\ 4 Water and Sanitation Agency, Government of Punjab, Lahore 54660, Pakistan \\ 5 Aerospace Malaysia Research Centre, Faculty of Engineering, Universiti Putra Malaysia, Serdang 43400, Malaysia
}

\section{ARTICLE INFO ABSTRACT}

\section{Article history:}

Received 31 May 2021

Received in revised form 5 August 2021

Accepted 8 August 2021

Available online 10 September 2021

\section{Keywords:}

Water leakage; Computational Fluid Dynamics; Drag Coefficient; Sensing Element

\begin{abstract}
The leakages in water pipeline networks sometimes negatively affect the environment, health, and economy. Therefore, leak detection methods play a crucial role in detecting and localizing leaks. These methods are categorized into internal and external detection methods, each having its advantages and certain limitations. The internal system has its detection based on the field sensors to monitor internal pipeline parameters such as temperature and pressure, thereby inferring a leak. However, the mobility of the sensing module in the pipeline is affected by the model drag coefficient. The low drag coefficient causes the module to quickly lost control in the pipeline leading to false detection. Therefore, this study is about designing and numerically analysing a new model to achieve a higher drag value of the sensing system. The drag value of various models is determined with the help of CFD simulations in ANSYS. The outcome of this study is a new model with a drag value of 0.6915 . It was achieved by implementing an aerodynamic shape, a more significant surface contact area in the middle, and canted fins at the front of the module. Both pressures, drag, and skin friction were increased, so a higher drag value of the sensing module can be achieved. Through this, the mobility and control of modules in the pipeline can be improved, improving leak detection accuracy.
\end{abstract}

\section{Introduction}

Due to the drastic reduction of global freshwater resources, cities in various countries have adopted plan measures such as water supply and tap water price adjustments to promote water conservation [1]. However, for underground water pipes leaking water has not yet attracted widespread attention. Leaking of underground water pipes is not easy to detect, but the loss is staggering. For example, In Pahang (Malaysia), the water loss rate caused by leaking water pipes is as high as $50 \%$, while the current national average is $35 \%$ which almost thrice that of developed

\footnotetext{
* Corresponding author.

E-mail address: aekamarul@upm.edu.my
}

https://doi.org/10.37934/arfmts.87.1.134150 
countries estimated by the World Bank, and is far from reaching the government's goal of reducing non-revenue water (NRW) to $25 \%$ by 2020 [1]. Water produced and lost before reaching the customer due to leaking pipes, illegal tapping or theft, and management issues is called non-revenue water (NRW) [2]. Besides, leakage of water pipes may cause problems such as lack of drinking water and ground subsidence [3]. These pipeline leak after-effects caused ground subsidence and sinkholes, which can destroy infrastructure such as roads, railways, highways [4]. Therefore, the current priority is how to reduce pipeline leakage through some methods and detect pipeline damage or leakage in time.

The localization technique like wave propagation, as shown in Figure 1(a) is essential for effective leak management and loss control [5-6]. The leak detection methods can be divided into internal and external leakage detection methods, as shown in Figure 1(b). The categories are based on the parameters used for the detection process [6]. The internal detection system uses internal pipeline parameters for leak detection, while the external ones use sensors placed outside and are high-risk methods because of system costs and complexity. Some external methods like vibroacoustic using hydrophones and accelerometers and pure vibrational techniques are well known in the industry [712]. Internal ones use field sensors for monitoring inside the control volume.

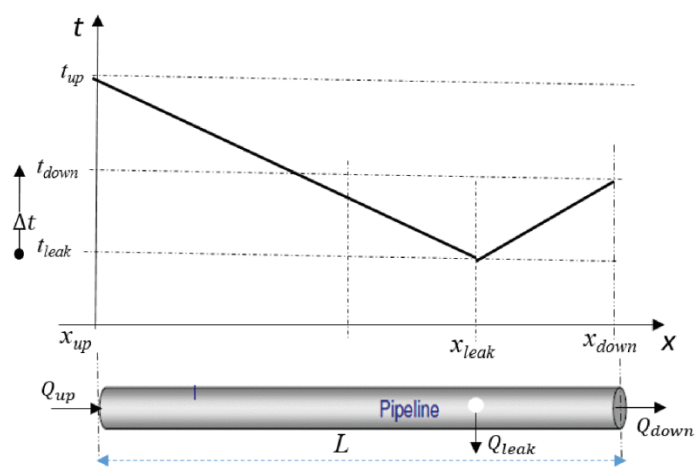

(a)

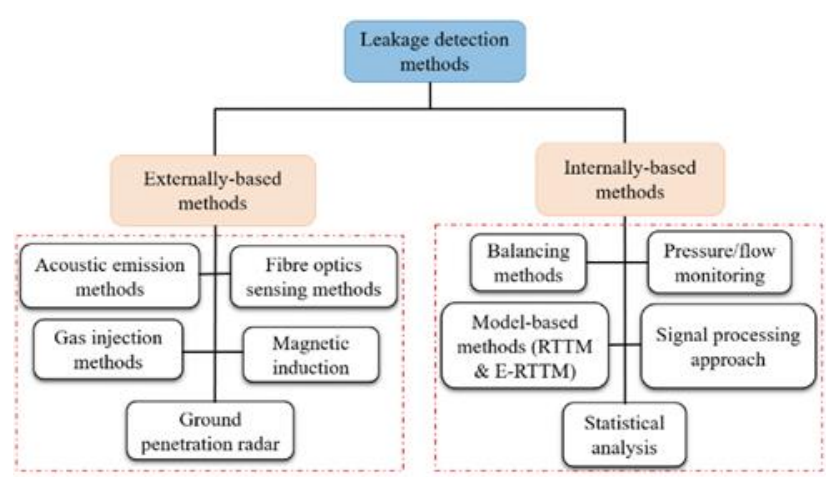

(b)

Fig. 1. (a) Wave propagation leak localization, (b) Categorization of few leak detection methods. [2017] IEEE. Reprinted, with permission, from Adedeji et al., [6]

In 2020, Solomon et al., [13] had patented a system and method for taking sensor measurement in the pipeline based on a noise leak correlator. Other than that, Yazdekhasti et al., [14] had reviewed in their research for various acoustic-based leak detection techniques (ALDTs), which include listening devices, noise loggers, leak noise correlators, free-swimming acoustic tethered acoustics, and acoustic emissions. Besides, El-Zahab and Zayed [15] also had reviewed the latest technology related to leakage detection by comparing different methods such as acoustic-based technique, infrared thermography, tracer gas, ground-penetrating radar, leak detecting robot, and wireless micro-electro-mechanical systems (MEMS).

Since Artificial Intelligence (AI) and the Internet of Things (IOT) began their advancement, the leak detection system also had integrated with this autonomous technology. For example, machine learning was also used to detect water leakage, as Abdelhafidh et al., [16] suggested in their research to use a cognitive loT-based architecture that used Apache Spark framework to maintain and process data from piezometric head and flow rate sensor. Through this, they can use machine learning to provide an accurate leak localization. Meanwhile, Lin et al., [17] introduced an intelligent pipeline leak detection and analysis system that uses ultrasonic meter' data for detection. This system was able to connect with the Android App interface and website interface. Furthermore, Bohorquez et al., [18] presented a new methodology that uses artificial neural networks (ANN) to successfully 
detect and detect leakage in pipes. Through the research, they demonstrate the potential of combining fluid transient waves and ANNs in leak detection.

A few standard methods were still preferred even with these advanced technologies when cost and simplicity were the foremost concerns. Wu et al., [19] done a more straightforward method by putting a sensor based on pressure gradient inside the pipeline for leakage detection. The same inside pipeline sensor method was studied by Dvajasvie et al., [20], which proposed using a robotic system capable of detecting low leakage rates because it was a reliable and low-cost system. This study would improve the sensor's mobility in the pipeline with the same concern in cost and simplicity. Mobility of the sensor is crucial as it could affect the accuracy of leak detection. Chatzigeorgiou et al., [21] concluded that design consideration inside the pipeline sensor needs to include size limitation, flow field characteristics, and functional and dexterity/maneuverability requirements. He also mentioned that CFD simulations could help determine the model's size and placement.

Thus, a new model of leakage sensor for detecting leakage from inside the pipeline is proposed in this study. The new model's performance was determined using Ansys Computational Fluid Dynamics (CFD) simulation and was validated based on a previous study by Zaki et al., [2]. The crucial parameter for performance evaluation is each simulated model's drag value because increasing the drag coefficient value would significantly increase the drag force. Based on previous research using CFD, Bai et al., [22] state that drag force depends on the shape of objects, its contact surface, and the increase with the square of incoming fluid velocity. They also mentioned that the pressure difference between the front and back could generate lift force, which assists the motion of a model. Besides this, Joung et al., [23] mentioned that drag is also influenced by the fineness ratio of a model, such as its length to the maximum diameter. Based on their study, conical shape outer shell has low drag compared to elliptical and ogive shape while similar mid-body shape had a higher drag. Therefore, considering these criteria of improvement into pipeline sensors, a higher drag design than the previous study can be achieved. Besides that, other consideration includes fabrication cost and difficulty. The significance of this study is to prevent and reduce water leakage in the pipeline by improving sensor detection using optimal motion of the module.

Through this study, the motion of the sensing module inside the pipeline can be improved. Thus, it would contribute to better water leaking detection inside the pipeline. Using this improved sensor, water pipeline-related companies can improve their efficiency in detecting water leaks and reduce overall cost in both inspection and preventing process.

\section{Methodology}

\subsection{Water Sensor Design}

The mobility module morphology with an outer shell structure is illustrated in Figure 2. For reference, the $100 \mathrm{~mm}$ diameter pipe has also been drawn. The main body and the four "stabilizing" front fins that pop out of the main body should be noticeable. The four front fins at angles of $90^{\circ}$ are set at equal distances and are canted outwards. It is possible to position the sensing element at the front nose or at the back of the module (it is located at the back in the chosen design), which is usually a sensitive hydrophone. The mobility module's external outer shell is a significant feature and a primary responsible shape factor influencing the drag coefficient. 


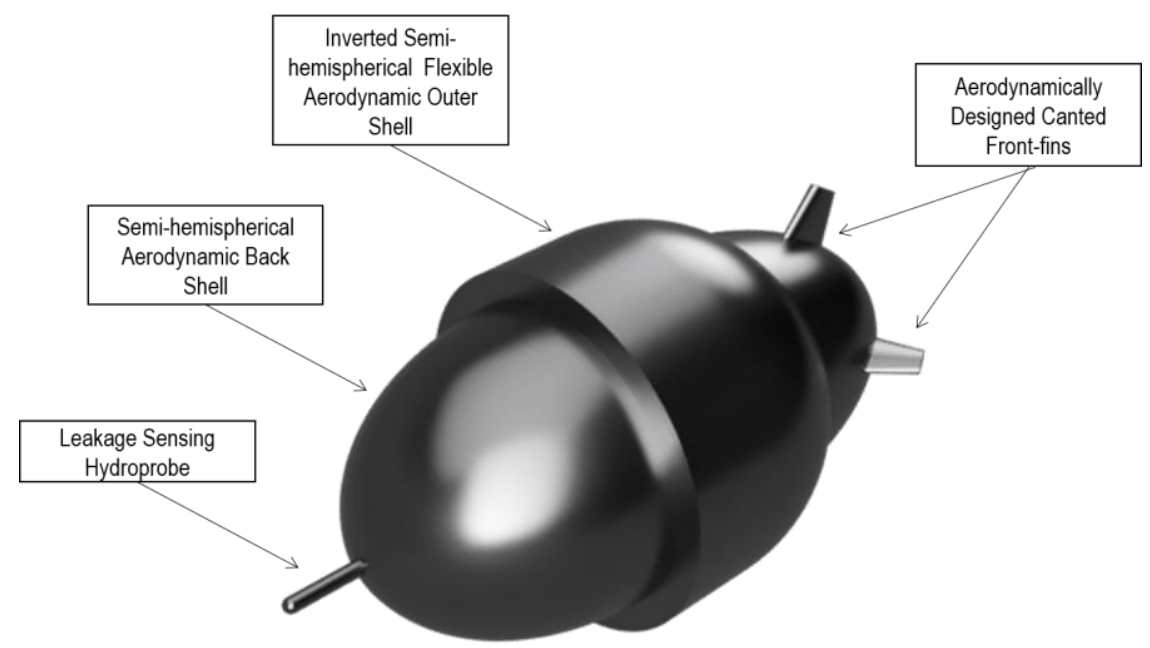

Fig. 2. Detailed morphology of the chosen design WSE-3 hulls after the numerical analysis shown at the end of this paper

\subsubsection{Design criteria}

The design criteria for the mobility module, including the control volume, is as follows (Table 1):

Table 1

Specific design criteria and their description

\begin{tabular}{ll}
\hline Criteria & Description \\
\hline Good Sensing & The sensing probe and its location should help in suitable sensing for leak detection \\
Ease of Manufacturing & The mobility module, including the control volume, should be easy to manufacture \\
Module Size & This paper looks at the specific size as per chosen design specifications in Table 2 \\
Free Floating & The module is floating in the pipe with a specific speed $V_{\text {Module }}$ inside the pipe \\
Speed Control & The module speed should always be less than the fluid to detect the leakages efficiently \\
Motion in control volume & The module needs to be able to move in the complex regions inside the control volume \\
Stability & This is the primary factor of design to stabilize itself against turbulence and CV walls
\end{tabular}

\subsubsection{Finally chosen designs}

Considering the design criteria mentioned above and using the morphological charts and Pugh matrix ranking system, the mobility module elements were designed and considered. This ranking system is a criteria-based decision matrix system that uses scoring to choose the solutions and rank them among several potential solutions. We used the morphological charts to determine different designs of fore-shells and back-shells of the leakage sensing modules, scored and therefore ranked them based on set criteria like durability, aerodynamics, assembling, drag force, etc. The entire water leakage sensing module is then categorized into three designs based on the location of the probe, frontal area of the hull structure, aerodynamic fins, etc. CATIA and AUTOCAD FUSION 360 were used to model the corresponding designs namely Water Sensor Element (WSE) -1, 2, and 3, as shown in Figure 3 below. The chosen design specifications as the primary requirement of all the three designs are mentioned in Table 2. 


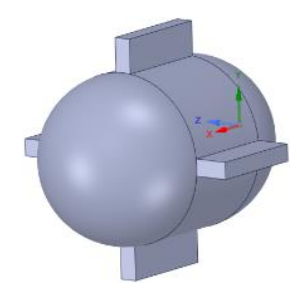

Design 1 - WSE-1

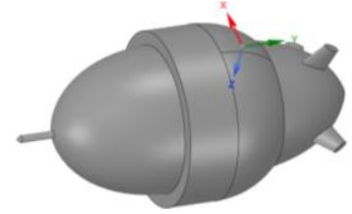

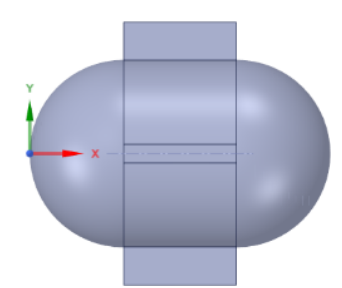

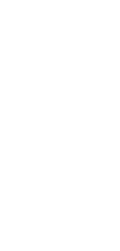

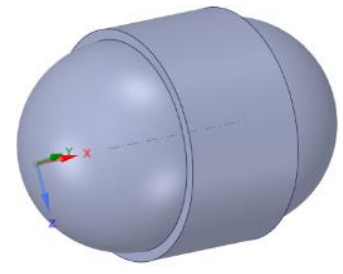

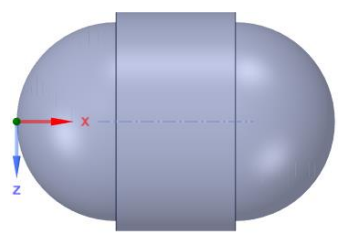

Design 2 - WSE-2

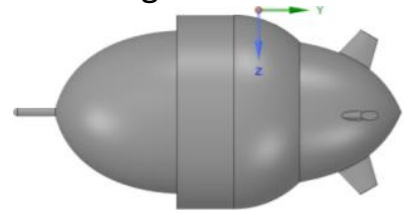

Design 3 - WSE-3

Table 2

Chosen design specifications of all the three designs

\begin{tabular}{lll}
\hline Design No. & Specification & Value \\
\hline Design WSE - 1 & Length of the Module & $80 \mathrm{~mm}$ \\
& Frontal Area of the Module & $0.00412783 \mathrm{~m}^{2}$ \\
& Length of the Sensing Element & $10 \mathrm{~mm}$ \\
Design WSE - 2 & Diameter (Main, Outer shell) & $50 \mathrm{~mm}, 70 \mathrm{~mm}$ \\
& Length of the Module & $80 \mathrm{~mm}$ \\
& Frontal Area of the Module & $0.00433932 \mathrm{~m}^{2}$ \\
& Length of the Sensing Element & $10 \mathrm{~mm}$ \\
Design WSE - 3 & Diameter (Main, Outer shell) & $50 \mathrm{~mm}, 55 \mathrm{~mm}$ \\
& Length of the Module & $85 \mathrm{~mm}$ \\
& Frontal Area of the Module & $0.00378536 \mathrm{~m}^{2}$ \\
& Length of the Sensing Element & $10 \mathrm{~mm}$ \\
& Diameter (Main, Outer shell) & $40 \mathrm{~mm}, 47.5 \mathrm{~mm}$ \\
\hline
\end{tabular}

The paper conducted a comprehensive flow visualization analysis on the mobility module within the water pipe, and the design selected is WSE-3 at the end. The outer shell structure is an inverted semi-hemispherical structure and is sufficiently flexible throughout complex regions to ease the module's movement within the pipe.

\subsection{Background Theory}

\subsubsection{Water flow in a pipe}

With ANSYS Academic Version, here at Faculty of Engineering, UPM, computational fluid dynamic simulations have been conducted. The software uses the Reynolds Average Naiver Stokes (RANS) equation to solve the fluid dynamic equations. In order to extract the mean flow properties from instantaneous ones, time averaging-RANS modeling can be helpful. For example, for the fully developed turbulent pipe flow velocity profile in Figure 4, the velocity components are like the sum of fluctuating components to the time-average component that provides instantaneous components. 


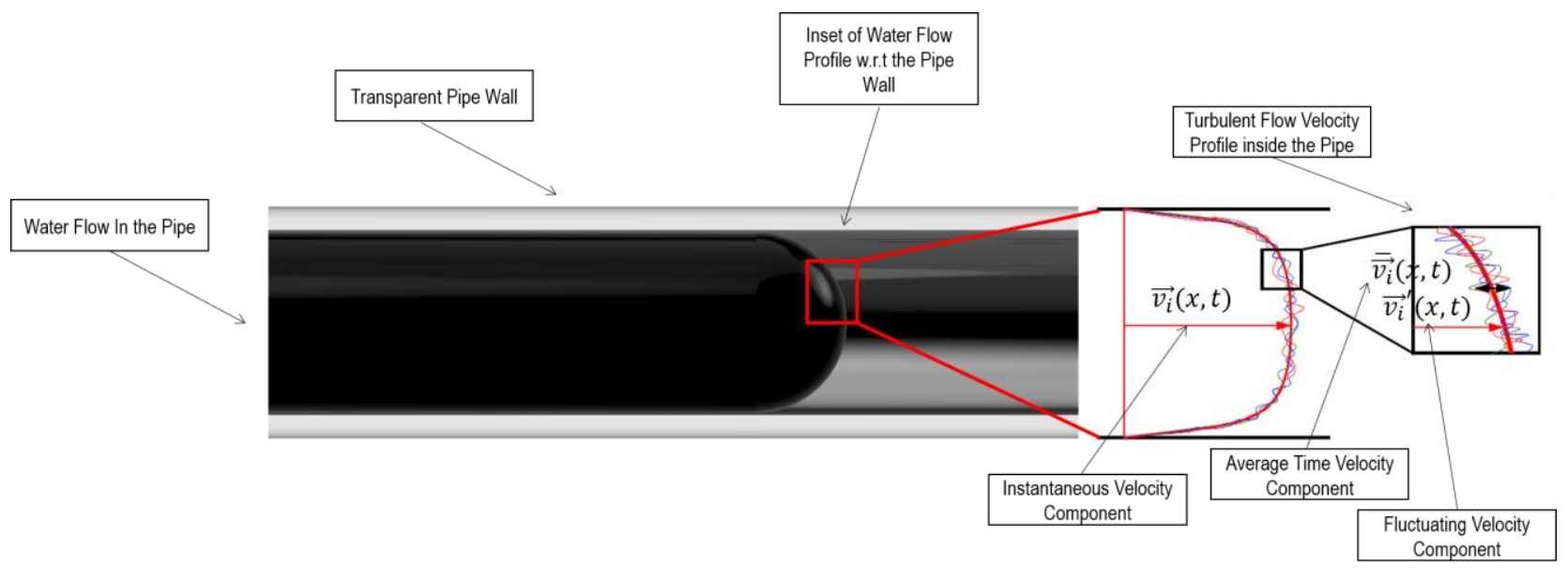

Fig. 4. Velocity profile of the fully developed turbulent water pipe flow [24]

The Reynolds-averaged momentum equation is

$\rho\left(\frac{\partial \overline{v_{\mathbf{l}}}}{\partial t}+\bar{v}_{k} \frac{\partial \overline{v_{\mathbf{l}}}}{\partial x_{k}}\right)=-\frac{\partial \overline{\boldsymbol{p}}}{\partial x_{i}}+\frac{\partial \overline{v_{\mathbf{l}}}}{\partial x_{j}}\left(\mu_{k} \frac{\partial \overline{v_{\boldsymbol{l}}}}{\partial x_{j}}\right)-\rho \frac{\partial{\overline{\bar{v}_{\boldsymbol{l}}}}^{\prime} \overline{\boldsymbol{v}}^{\prime}}{\partial x_{j}}$

The pressure distribution across the body, velocity vectors, and the drag coefficient measurement, transient state 3D turbulent flow simulations were used to analyze the flow field. As per reference, the standard $k-\varepsilon$ model is used here for turbulence, and the boundary conditions of the inlet velocity and pressure outlet are applied [24]. The transport equations for both $k$ and $\varepsilon$ are

$$
\begin{aligned}
& \frac{D}{D t}(\rho k)=\frac{\partial}{\partial x_{i}}+\left[\left(\mu+\frac{\mu_{t}}{\sigma_{k}}\right) \frac{\partial k}{\partial x_{j}}\right]+G_{k}-\rho \varepsilon \\
& \frac{D}{D t}(\rho \varepsilon)=\frac{\partial}{\partial x_{i}}+\left[\left(\mu+\frac{\mu_{t}}{\sigma_{\varepsilon}}\right) \frac{\partial \varepsilon}{\partial x_{j}}\right]+A \frac{\varepsilon}{k} G_{k}-\rho B \frac{\varepsilon^{2}}{k}
\end{aligned}
$$

\subsubsection{Water sensor motion characteristics}

As far as the mobility of the system is concerned, as shown in Figure 5, the mobility module appears to be stationary concerning the moving axis frame; water seems to flow with the relative velocity $V_{\text {Relative }}=V_{\text {Flow }}-V_{\text {Module }}\left(V_{\text {Module }}<V_{\text {Flow }}\right)$ and the pipe seems to be moving with a velocity of $V_{\text {Wall }}=V_{\text {Module }}$ to the left. This research is used for force measurements and later for flow (CFD) simulations. The total drag force is dependent on this relative velocity as:

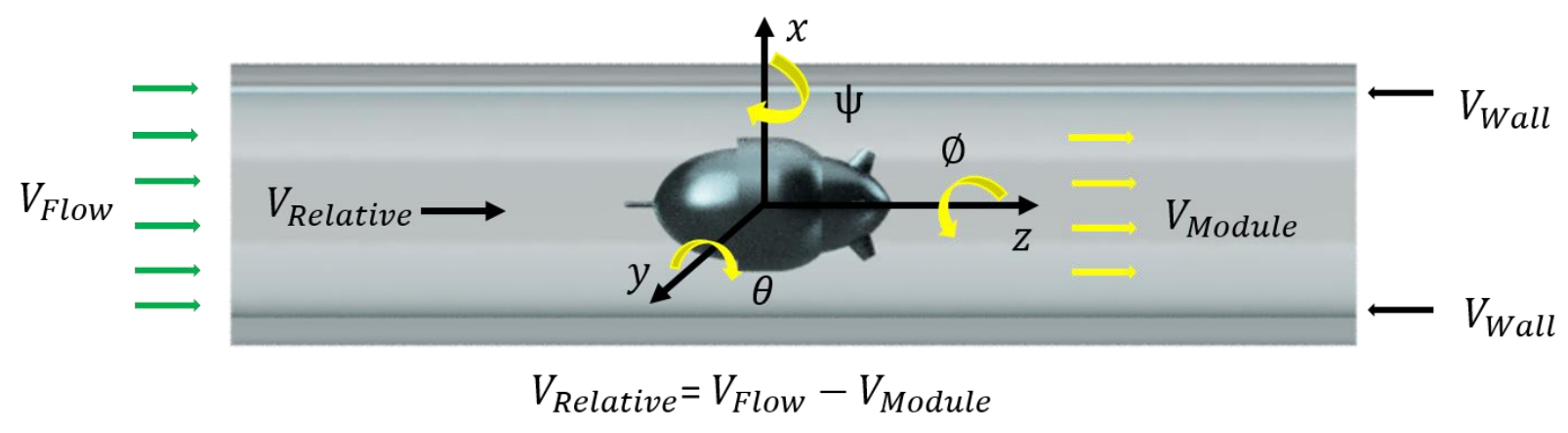

Fig. 5. Motion specifications of the sensing module hull inside the water pipe [21] 


$$
F_{D}=\frac{1}{2} \rho V_{\text {Relative }}{ }^{2} C_{D} A_{R}
$$

The module is applied counter force to aid its unique outer shell structure to withstand this force and regulate its speed, making the designed module less complicated, producing enough drag, and is highly effective. This is an essential aspect of leakage detection and communication.

The outer shell is carefully built as a flexible element and helps place constraints on the $x$ and $y$ axis, placing constraints on the mobility module's 2-degree of freedom components $\psi$ and $\theta$ to allow the module to float freely along with the flow. Therefore, the module is always in the center of the pipe segment and travels smoothly along the $z$ axis, and is stable at all times.

\subsection{CFD Process and Meshing}

As shown in Figure 6, current CFD computations of the complete system have been carried out on a denser grid near the main study area. The grid consists of 136158 number of nodes and 730480 number of elements and is tuned to the freestream conditions inside the pipe.

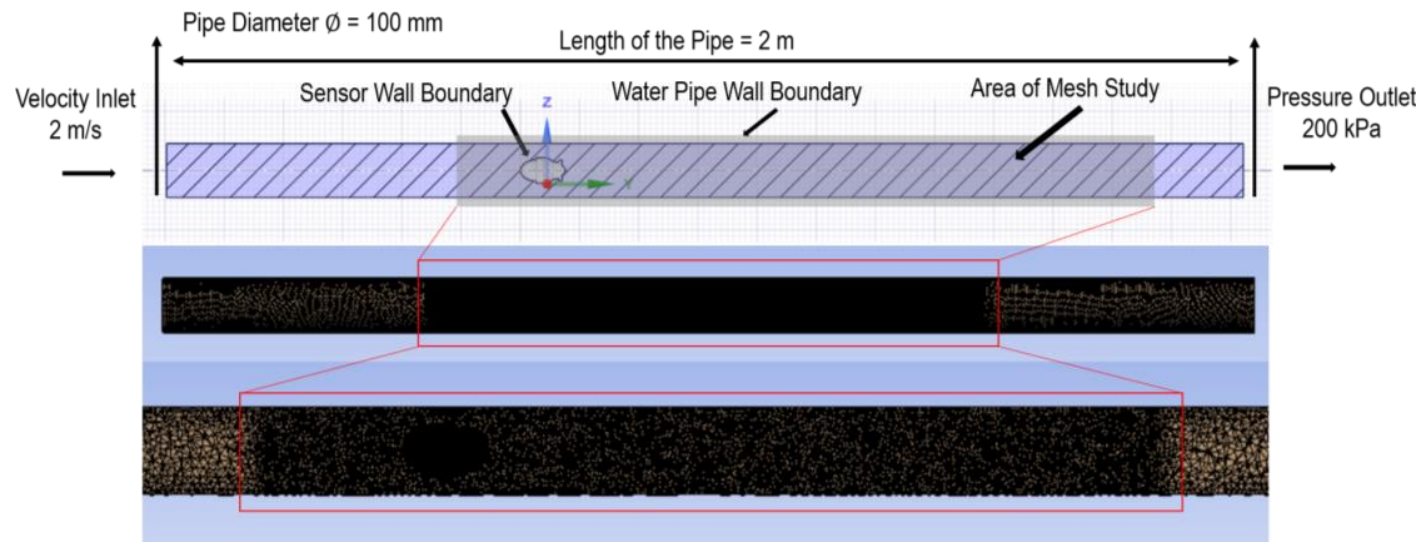

Fig. 6. Model and meshing characteristics with chosen mesh study area

According to the computational scope, the distribution of the surface grid points was determined by the degree of resolution required in different areas near the module and in the front, such as the area near the module and beyond the front nose. Figure 7 shows a close-up view of the semistructured 3D mesh on the surface of the module. A solution-adaptive approach has been used to refine grids in high gradient regions of the flow area.

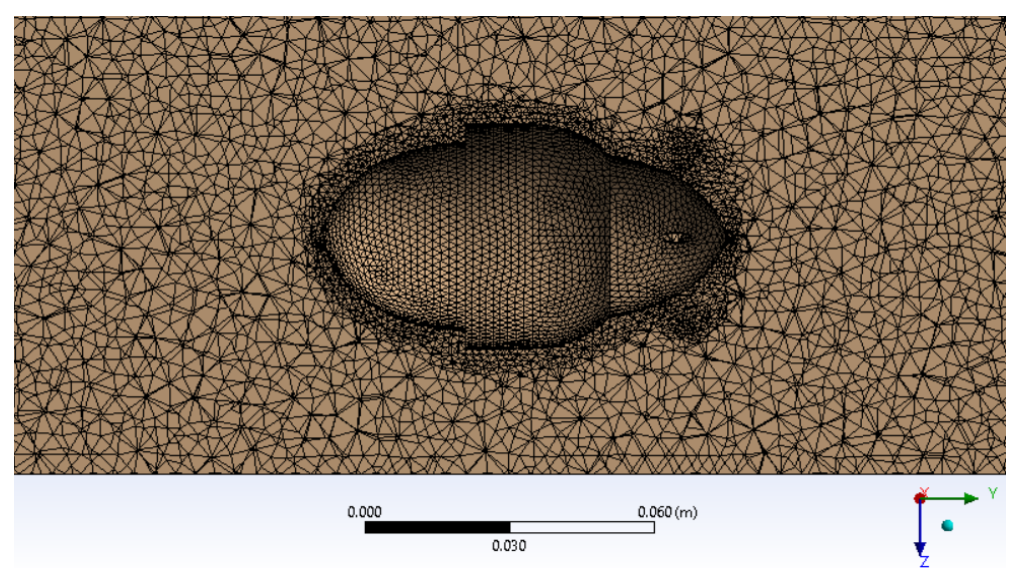

Fig. 7. Meshing near the boundary wall of the sensing module inside the control volume 


\subsection{Grid and Time-Step Independence Study}

First, a grid independence study must decide the 'right' mesh size chosen in the numerical simulations. Generally, for capturing variations in flow properties, a denser mesh is favored and is more attractive. A very fine mesh or dense mesh, however, requires significantly greater computer resources and time. By performing this grid independence study, a consensus is found, and the outcomes can be seen.

In Table 3, the meshing characteristics of the various levels of mesh sharpness can be found. As medium and fine meshes are applied, it can be seen that the variation of the coefficient of drag value is much more considerable than that predicted by using a coarser mesh. There is no significant difference between the medium and fine mesh. The mesh with a medium degree of fineness (Mesh 3 in Table 3) is selected to save computational resources. Similarly, the independence study of the time-step size on the computed results is performed using three different time-steps: $1,0.1,0.01$ seconds concerning the computed coefficient of Drag Value as shown in Table 4 below.

Table 3

Grid Independence Study

\begin{tabular}{llll}
\hline Mesh Number & Number of Nodes & Number of Elements & Drag Coefficient \\
\hline Mesh 1 & 51325 & 265508 & 0.6060 \\
Mesh 2 & 73741 & 385595 & 0.6561 \\
Mesh 3 & 136158 & 730480 & 0.6915 \\
Mesh 4 & 231706 & 1268140 & 0.7035 \\
\hline
\end{tabular}

Table 4

Time Independence Study

\begin{tabular}{ll}
\hline Time Step Size $(s)$ & Drag Coefficient \\
\hline 1 & 0.6915 \\
0.1 & 0.6922 \\
0.01 & 0.6921 \\
\hline
\end{tabular}

\section{Results}

\subsection{Validation of Designed Model}

A CFD simulation was first performed for validation purposes on Chatzigeorgiou et al., [21] comparable previous work. The drag coefficient endured by the original design was determined from the validation process. The validation results provided a drag coefficient of 0.20 from the mesh characteristics in Table 5, while the actual results were at 0.1984 , which means a 0.8 percent error. Since the error is below $10 \%$, the findings are considered reliable and confirmed.

Table 5

Validation characteristics

\begin{tabular}{lll}
\hline Characteristics & Original & Validation \\
\hline Maximum Skewness Factor & 0.81 & 0.79584 \\
Average Skewness Factor & 0.22 & 0.22193 \\
Length of the Mobility Module & $125 \mathrm{~mm}$ & $125 \mathrm{~mm}$ \\
Length of the Pipe & $2 \mathrm{~m}$ & $2 \mathrm{~m}$ \\
Diameter of the Pipe without legs & $60 \mathrm{~mm}$ & $60 \mathrm{~mm}$ \\
Drag Coefficient & 0.1984 & 0.20 \\
\hline
\end{tabular}




\subsection{The Coefficient of Drag}

The drag coefficient was determined for each design using CFD simulations and equated as shown in Table 6. Design 1 has the lowest drag coefficient comparable to other designs. This design's main body is similar to the Chatzigeorgiou et al., [21], as a cylindrical shape. The drag coefficient value for this design is higher than the reference body because of the addition of four fins located on the surface of the main body. The front view of fins is like a flat, thin rectangular plate known to offer maximum drag.

\section{Table 6}

The value of Drag Coefficient from CFD analysis of each design

\begin{tabular}{ll}
\hline Design Number & Drag Coefficient $C_{D}$ \\
\hline Reference Design (Validation) & 0.1984 \\
Design 1 - WSE -1 & 0.4049 \\
Design 2 - WSE -2 & 0.5880 \\
Design 3 - WSE -3 & 0.6915 \\
\hline
\end{tabular}

Design 2 has a higher drag coefficient than the reference design and design 1 . The dimensions of the main body are similar to design 1 . However, the outer shell's addition to the main body instead of fins was the reason for the drag to elevate. The outer shell's front view is like a spherical or cylindrical plate, which offers more frontal area to enhance the drag coefficient comparable to the fin model.

The highest drag value was noticed from the simulations of design 3, which has the basic shape of a rugby ball containing the four aerodynamically shaped fins at the leading edge for its stability in the turbulence region. This design also contains an outer shell like in design 2 , with a slight increase in the outer shell thickness, it offered more frontal area and consequently boosted drag coefficient. The beneficial aspect is that the existence of more surface and frontal area creates an interference with the streamline flow, slowing down the module's motion at a suspicious position to have more time to detect leakage.

\subsection{Pressure and Velocity Contours}

Figure 8(a) and Figure 8(b) displays the contours of velocity and pressure, respectively, surrounding the body of design 1 for a relative velocity of $2 \mathrm{~m} / \mathrm{s}$. Velocity contours show that as the flow passes the module, the stream reports a loss of symmetry in the wake resulting in the eddies that convected in the wake region. However, this does not produce the alternating separation of the vortices due to the weak recirculation region. As expected, velocity is maximum in the clearance portion between the pipe wall and module material. The sensor's location in the module body is also an essential factor for better safety and accuracy. The pressure distribution clearly shows that attaching the sensor to the main body in the clearance between the body and the pipe is not correct due to high-pressure gradient in this region. It can also be observed that maximum pressure occurs at the point of contact where the velocity at that point is zero. The pressure is reduced in the clearance area on the body's side, where the relative velocity is found to be highest. 


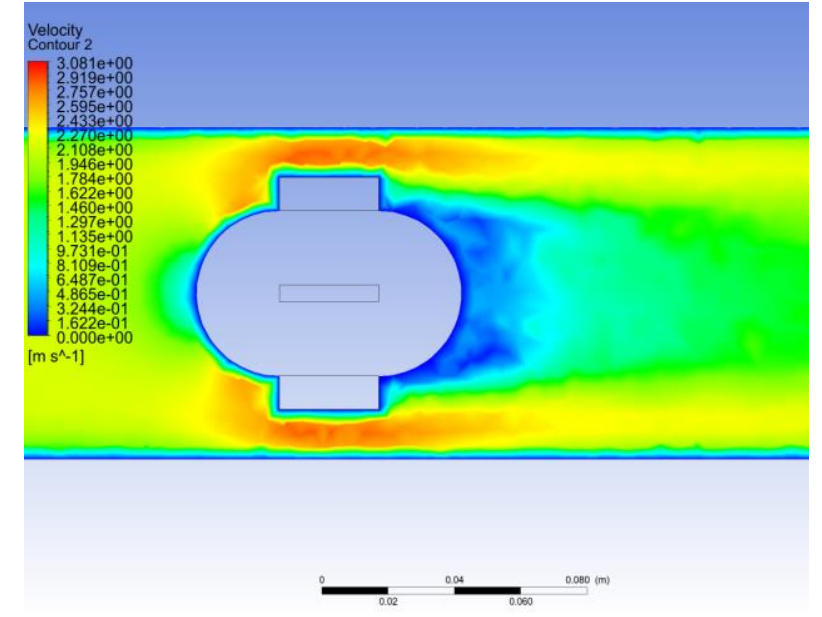

(a)

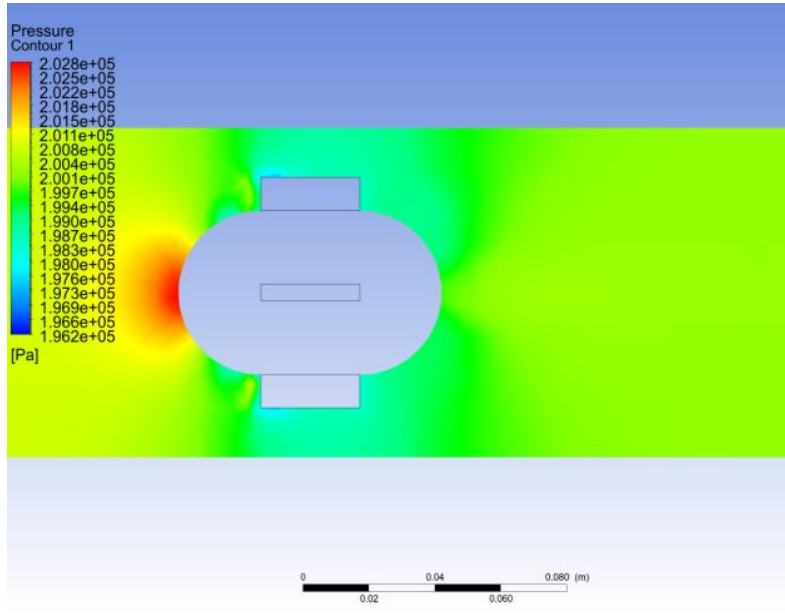

(b)

Fig. 8. Velocity and Pressure Contours of design WSE - 1 at a relative velocity of $2 \mathrm{~m} / \mathrm{s}$ from left to right. This design has straight vertical fins perpendicular to each other

Figure 9(a) and Figure 9(b) displays the contours of velocity and pressure, respectively, surrounding the body of design 2 for a relative velocity of $2 \mathrm{~m} / \mathrm{s}$. Velocity contours show that as the flow passes the module, stream reports a loss of symmetry again in the wake, resulting in the eddies convected in the wake region. Like design 1, this also does not produce the alternating separation of the vortices due to the weak recirculation region. Due to the addition of the outer shell to the main body, shallow velocity was observed near the module's surface compared to the velocity in the clearance region. This velocity distribution tries to slow down the module in a practical case, resulting in a drag increase. Again, it can also be observed that maximum pressure occurs at the point of contact where the velocity at that point is zero. The pressure is developing in the clearance area on the side of the body and slightly decreasing at the edges of the outer shell, which means the highest relative velocity location, which again contributes to drag increase.

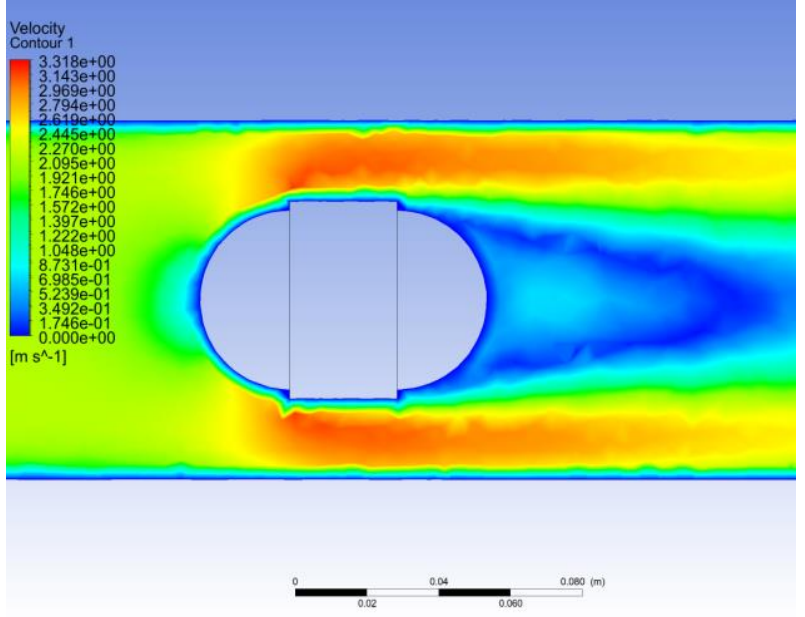

(a)

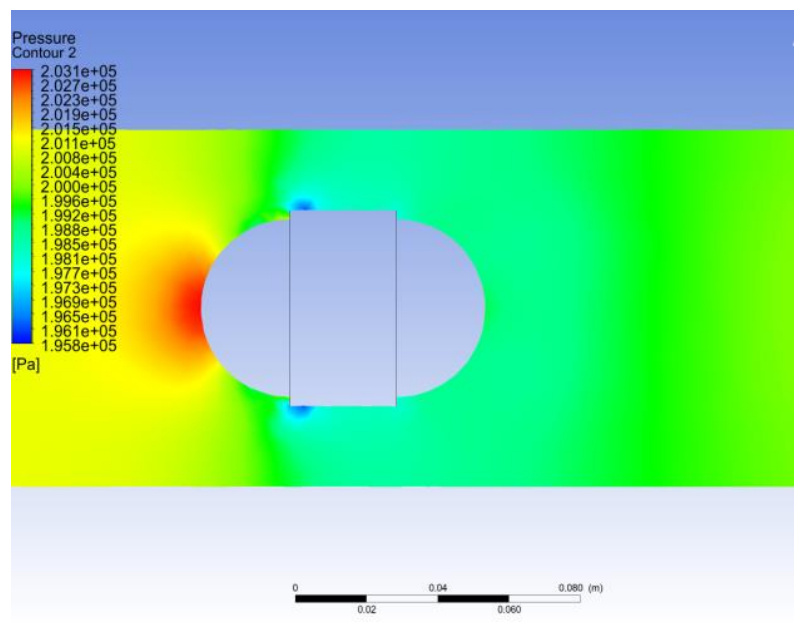

(b)

Fig. 9. Velocity and Pressure Contours of design WSE -2 at a relative velocity of $2 \mathrm{~m} / \mathrm{s}$ from left to right. This design has an outer shell structure of significantly less diameter surrounding the module from the center and is symmetric 
Figure 10(a) and Figure 10(b) displays the contours of velocity and pressure, respectively, surrounding the body of design 3 for a relative velocity of $2 \mathrm{~m} / \mathrm{s}$. This design is carefully made to ensure that the configuration itself is sufficient to impact the module velocity. As expected, velocity contours show zero velocity at the point of contact and maximum velocity between the module and pipe wall clearance. The maximum velocity obtained in the clearance region for this design was 3.323 $\mathrm{m} / \mathrm{s}$, which is the highest compared to all other designs.

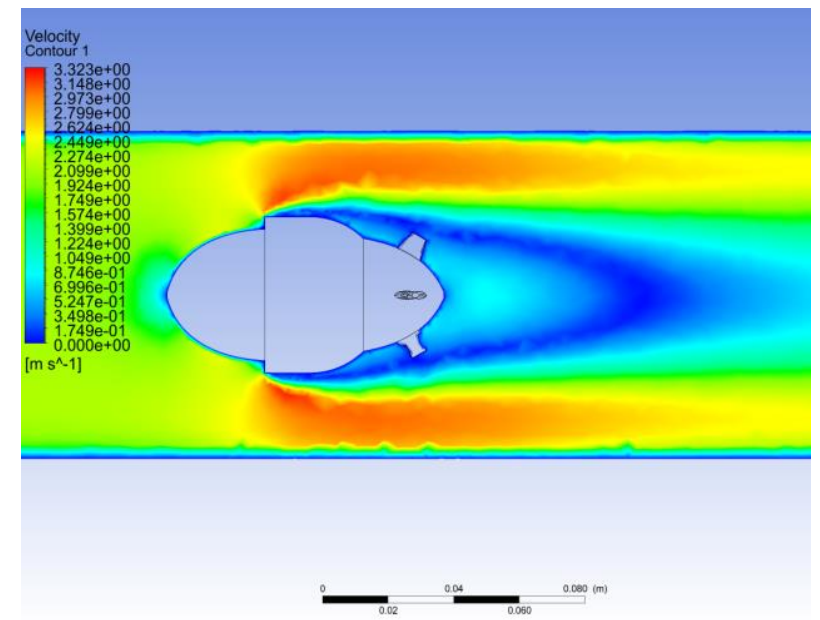

(a)

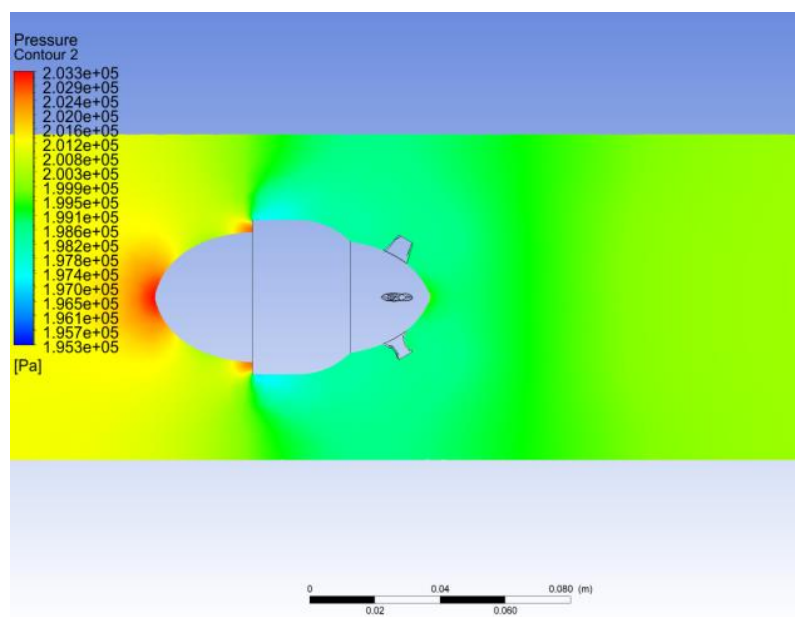

(b)

Fig. 10. Velocity and Pressure Contours of design WSE -3 at a relative velocity of $2 \mathrm{~m} / \mathrm{s}$ from left to right. This design has an outer shell structure with a diameter surrounding the center's module and fins at the nose

The outer shell covering the main body acts like brakes to slow down the module for a longer time at leakage detection. The wake region was also shown in velocity contours, but it was not strong enough to cause vortex shedding and tried to regain its stream afterward. Pressure contours display that the maximum pressure occurs at the point of contact. High pressure was also encountered on the surface of the outer shell facing the moving water, and a high-pressure gradient was observed afterward. The pressure descends toward the rear end along the body's sides, where the relative velocity is found to be highest. This is the best-chosen design.

\subsection{Sensitivity Analysis}

To further enhance the numerical analysis completed above for the designed water sensor module, sensitivity analysis was carried out to measure susceptibility to changes in the drag with the variation in relative flow velocity and to determine how sensitive the results are to these variations. This type of Sensitivity Analysis (SA) is used in numerical modeling to assess the effects of uncertainties in one or more input variables, such as flow velocity, on the output variable, drag. This analysis is beneficial because it enhances or reduces the model's prediction by investigating qualitatively and/or quantitatively the model's response to a change in input variables or by better comprehending the phenomena by evaluating interactions between variables between drag, velocity, and pressure.

Figure 11(a) represents the pressure contours of the sensing module WSE -1 at relative flow velocity from $1 \mathrm{~m} / \mathrm{s}$ to $4 \mathrm{~m} / \mathrm{s}$, whereas Figure 11(b) represents the velocity contours of the sensing module WSE - 1 at relative flow velocity from $1 \mathrm{~m} / \mathrm{s}$ to $4 \mathrm{~m} / \mathrm{s}$. Figure 12 (a) represents the pressure contours of the sensing module WSE - 2 at relative flow velocity from $1 \mathrm{~m} / \mathrm{s}$ to $4 \mathrm{~m} / \mathrm{s}$, whereas Figure 
12(b) represents the velocity contours of the sensing module WSE -2 at relative flow velocity from $1 \mathrm{~m} / \mathrm{s}$ to $4 \mathrm{~m} / \mathrm{s}$.

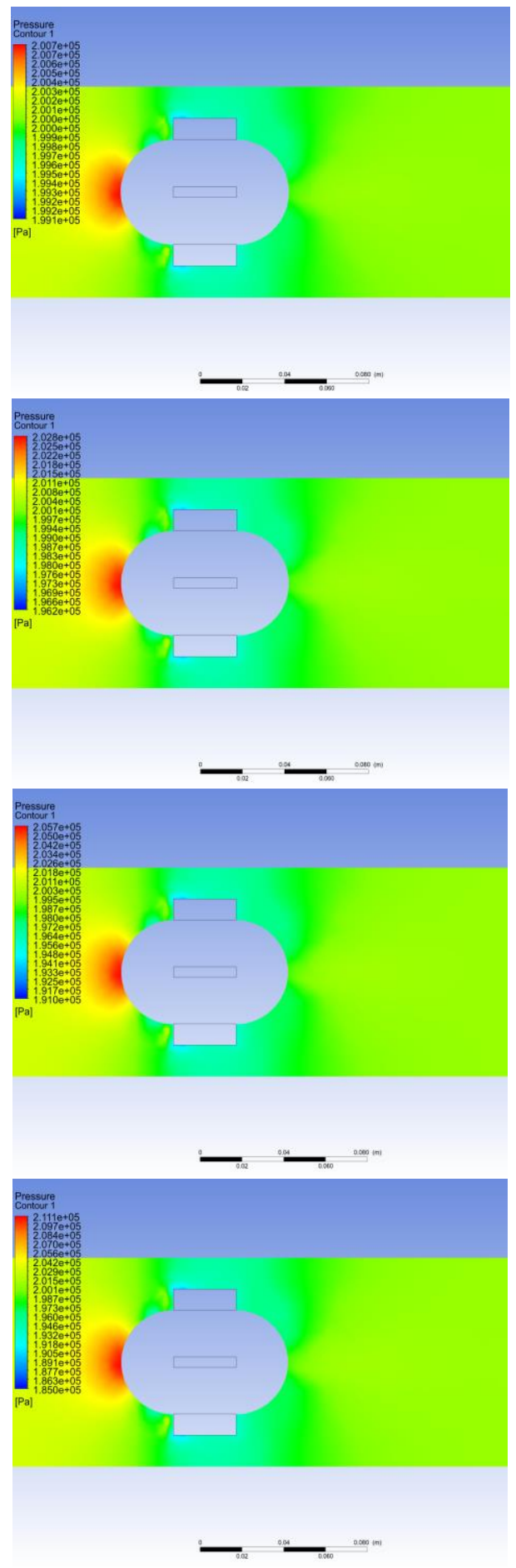

(a)

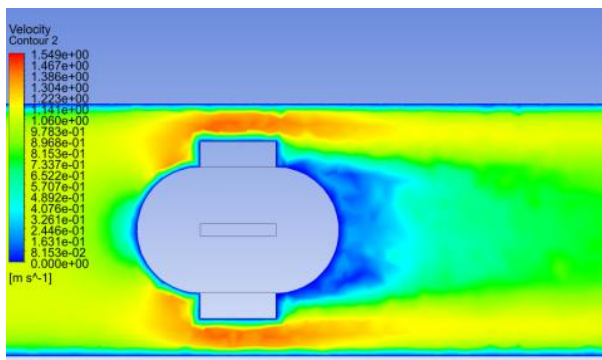

-
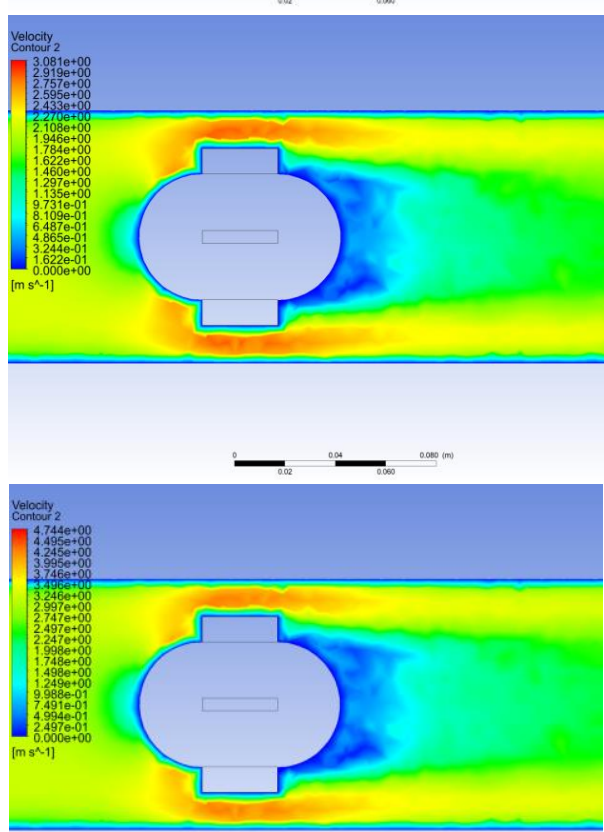

$-1-\cos m$

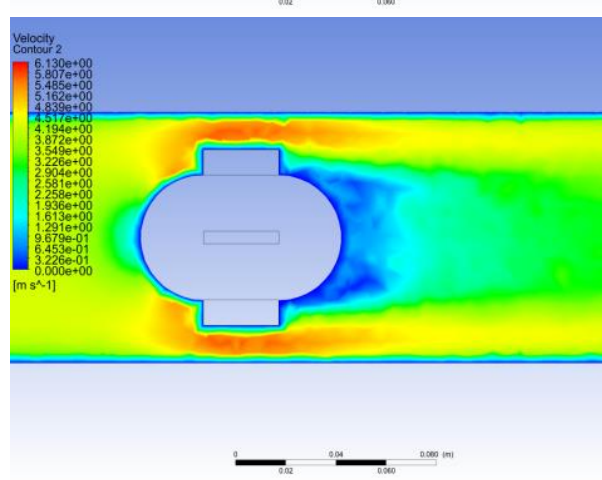

(b)

Fig. 11. (a) Pressure Contours of design WSE -1 at a relative velocity of $1 \mathrm{~m} / \mathrm{s}$ to $4 \mathrm{~m} / \mathrm{s}$ from top to bottom (b) Velocity Contours of design WSE -1 at a relative velocity of $1 \mathrm{~m} / \mathrm{s}$ to $4 \mathrm{~m} / \mathrm{s}$ from top to bottom. These simulations are used for sensitivity analysis 


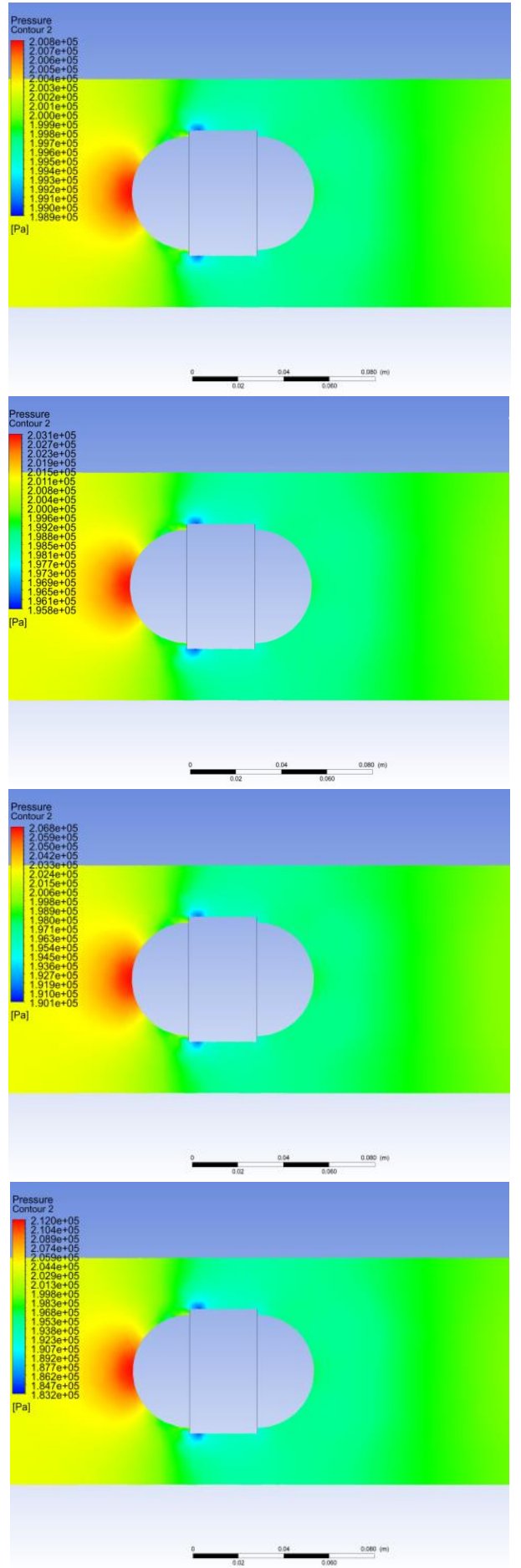

(a)
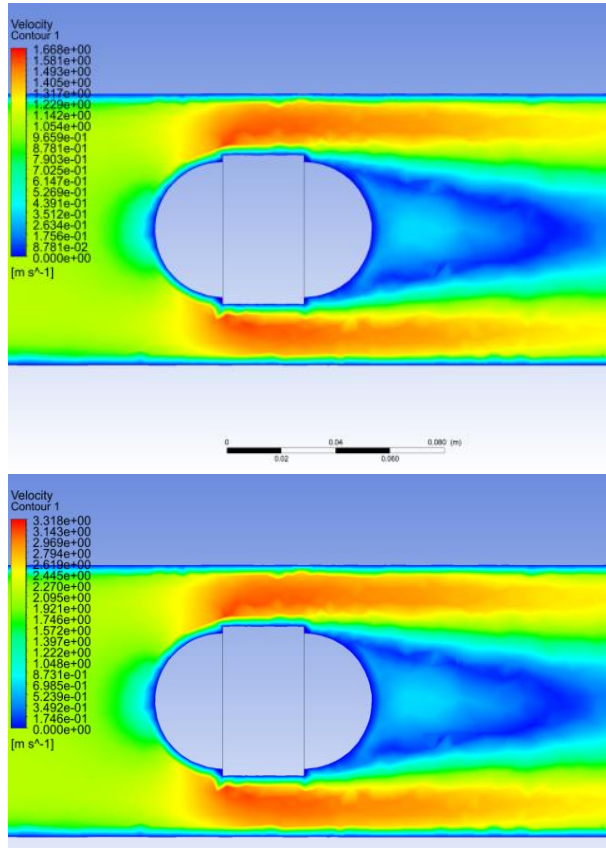

$\longrightarrow$ -

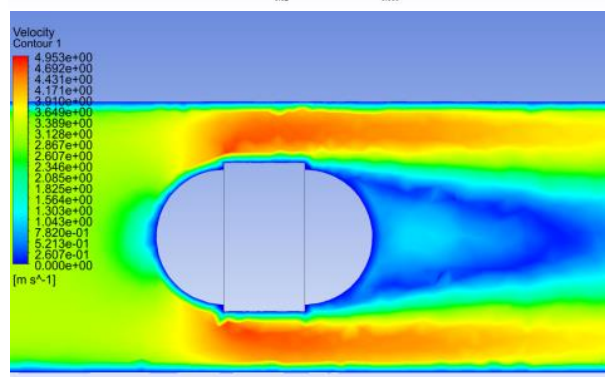

$-\ldots$

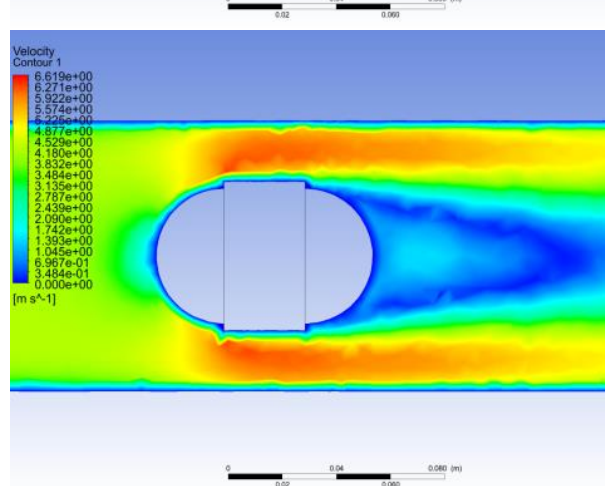

(b)

Fig. 12. (a) Pressure Contours of design WSE -2 at a relative velocity of $1 \mathrm{~m} / \mathrm{s}$ to $4 \mathrm{~m} / \mathrm{s}$ from top to bottom (b) Velocity Contours of design WSE -2 at a relative velocity of $1 \mathrm{~m} / \mathrm{s}$ to $4 \mathrm{~m} / \mathrm{s}$ from top to bottom. These simulations are used for sensitivity analysis

Figure 13(a) represents the pressure contours of the sensing module WSE - 3 at relative flow velocity from $1 \mathrm{~m} / \mathrm{s}$ to $4 \mathrm{~m} / \mathrm{s}$, whereas Figure 13(b) represents the velocity contours of the sensing module WSE - 1 at relative flow velocity from $1 \mathrm{~m} / \mathrm{s}$ to $4 \mathrm{~m} / \mathrm{s}$. The results were carried out to examine the coefficient of drag value at each value of relative velocity to understand its impact on the results' sensitivity. It was observed that the coefficient of drag significantly decreases for designed modules 
WSE -1 and WSE - 2 as the flow velocity increases and increases gradually for the designed module WSE -3.

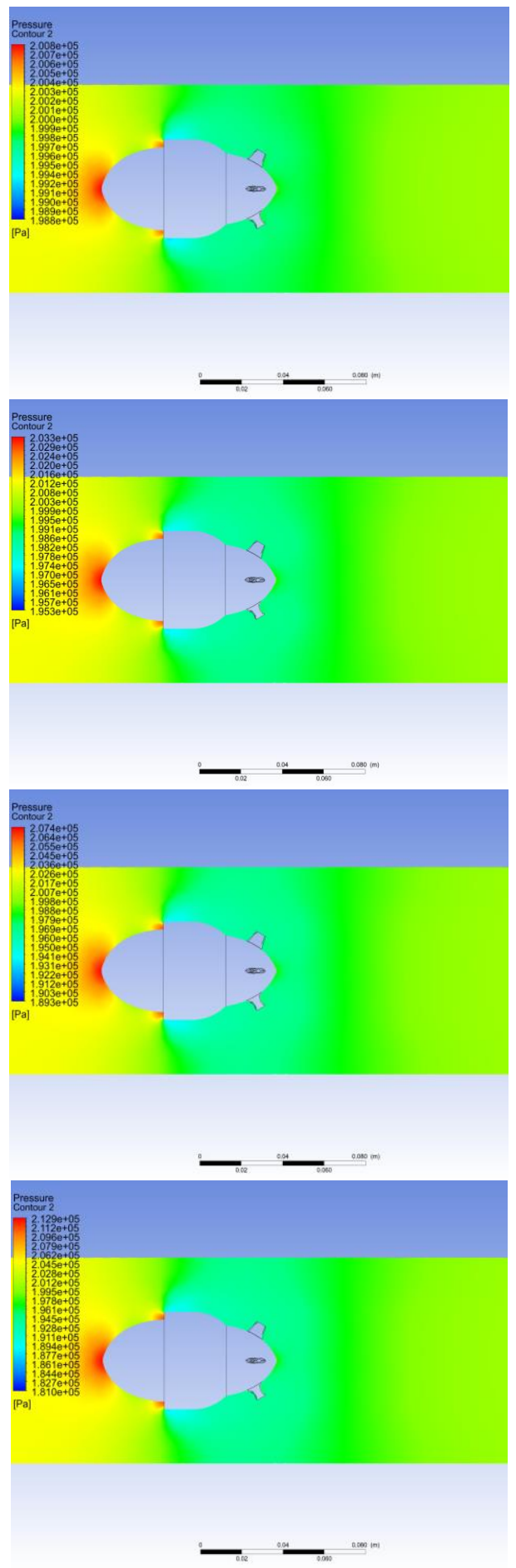

(a)
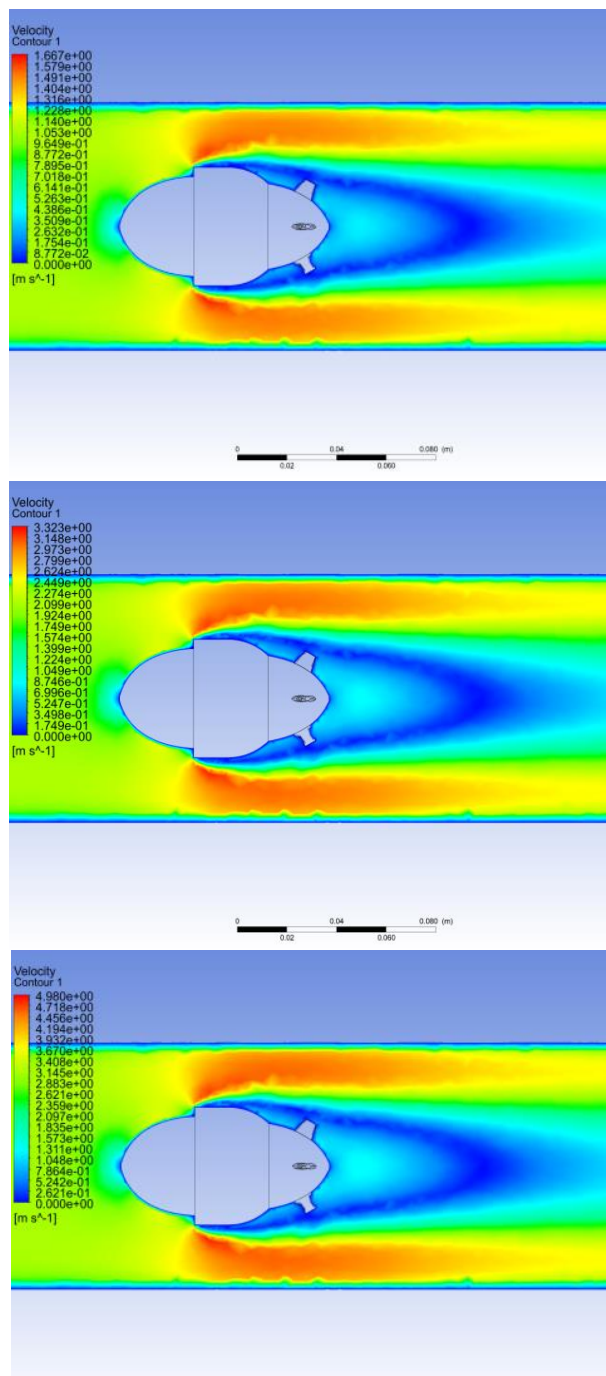

$-1-\cos m$

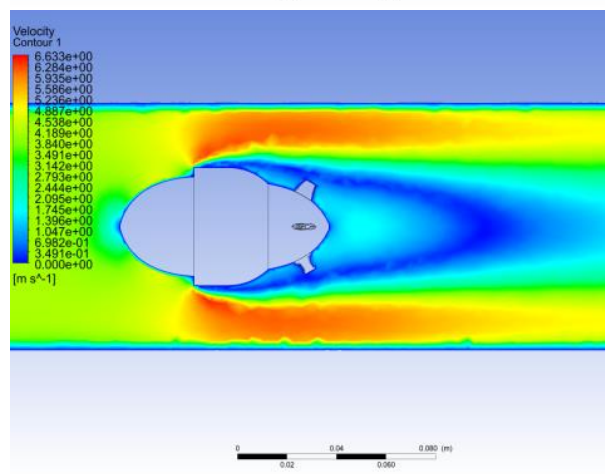

(b)

Fig. 13. (a) Pressure Contours of design WSE -3 at a relative velocity of $1 \mathrm{~m} / \mathrm{s}$ to $4 \mathrm{~m} / \mathrm{s}$ from top to bottom (b) Velocity Contours of design WSE -3 at a relative velocity of $1 \mathrm{~m} / \mathrm{s}$ to $4 \mathrm{~m} / \mathrm{s}$ from top to bottom. These simulation are used for sensitivity analysis 
This observation gives the design point velocity of $2 \mathrm{~m} / \mathrm{s}\left(C_{D}\right.$ range between $0.40-0.7$ ) from where this significant change happens, thereby making the design an optimal one for the results carried out for numerically accessing the water sensor module designed for leakage analysis in water pipeline networks, as shown in Figure 14(a) to Figure 14(c). In other words, the expected values of these parameters involved can be used to assess the robustness, or 'sensitivity', of the results with these changes, and to determine the values beyond which the results dramatically change like in this case at a chosen design point of $2 \mathrm{~m} / \mathrm{s}$.

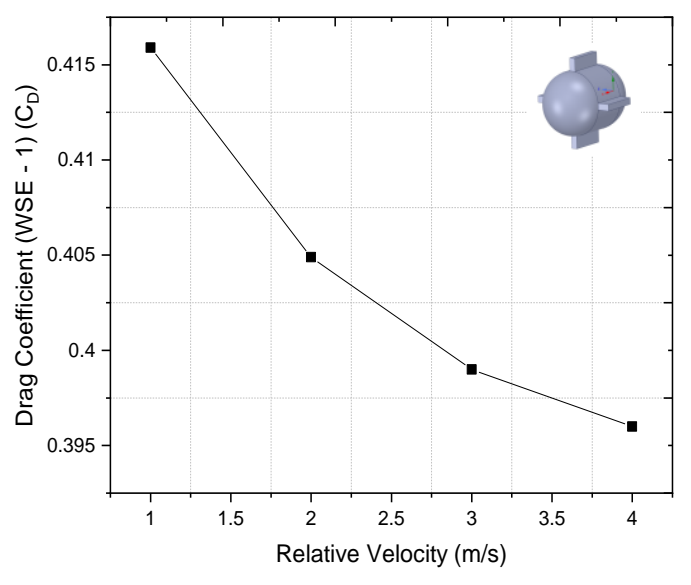

(a)

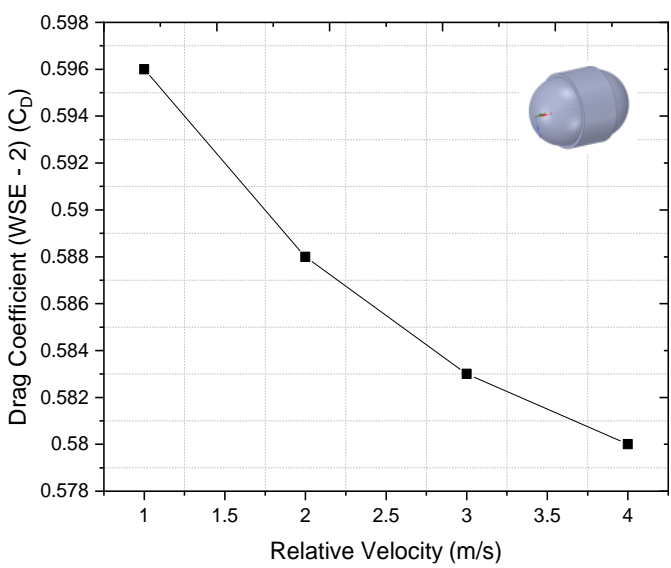

(b)

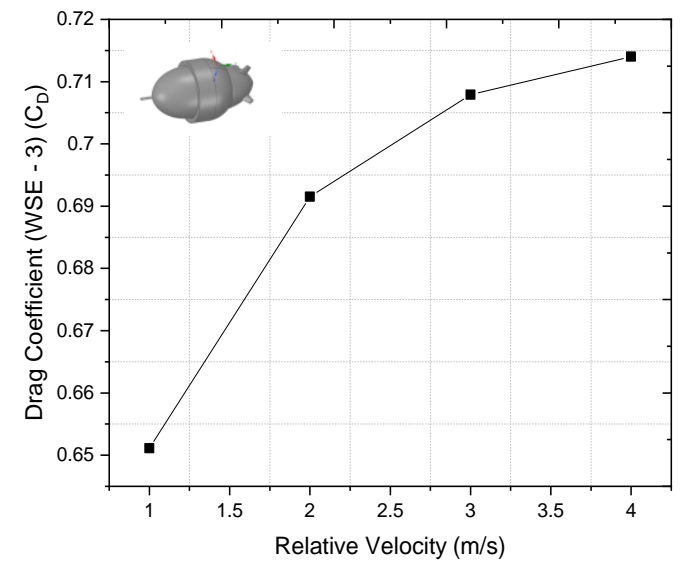

(c)

Fig. 14. Variation of drag coefficient $\left(C_{D}\right)$ with the change in relative flow velocity for module design (a) WSE - 1 (b) WSE - 2 and (c) WSE - 3

This sensitivity analysis highlights the most critical requirements for increasing design specifications, resulting in a switch from design 1 and design 2 to design 3. Indeed, our research reveals that pressure, velocity, and drag are key attributes in this case.

\section{Conclusions}

The concept of a safe, free-floating water pipe leak detection device has been addressed in this paper. Some important factors need to be considered in the design of such modules, such as size, flow field characteristics, sensing power, motion characteristics, and stability. In sizing the module and deciding on the sensor's location, CFD simulations can be constructive. Using CFD simulations, three different shapes of leakage sensors have been developed and analyzed. WSE - 3 was the best design of the mobility module with a sensing element, generating the highest drag coefficient, 
resulting in higher stability. The findings indicate that the capacity to travel inside the water pipeline network is accessible in all three situations. Though the numerical simulations are adequately validated, for a more comprehensive study, it would always be better to validate the design and the process using experimental analysis, making the rigs, and physically testing it. It is necessary to explore in the future how various subsystem modules, such as sensing, data acquisition, communication, etc., can be integrated with this built module, the most challenging task. It is also essential to look into sharing data and making the module more autonomous within the flow.

\section{References}

[1] Thajudeen, Kulsanofer Syed. "The Malaysian Leaky Pipe Story." The Malaysian Reserve, February 3, 2020. https://themalaysianreserve.com/2020/02/03/the-malaysian-leaky-pipe-story/

[2] Zaki, Muhammad Mirza Mohd, Turki Al Qahtani, Noorfaizal Yidris, Shamsuddin Sulaiman, Ahmad Hamdan Ariffin, Mohd Saffuan Yaakob, and Kamarul Arifin Ahmad. "Design and Analysis of a Water Pipe Leakage Sensor." CFD Letters 12, no. 9 (2020): 51-59. https://doi.org/10.37934/cfdl.12.9.5159

[3] Karoui, Tarek, Seong-Yun Jeong, Yeong-Hoon Jeong, and Dong-Soo Kim. "Experimental study of ground subsidence mechanism caused by sewer pipe cracks." Applied Sciences 8, no. 5 (2018): 679. https://doi.org/10.3390/app8050679

[4] Kwak, Pill-Jae, Sang-Hyuk Park, Chang-Ho Choi, Hyun-Dong Lee, Jae-Mo Kang, and In-Hwan Lee. "IoT (Internet of Things)-based underground risk assessment system surrounding water pipes in Korea." International Journal of Control and Automation 8, no. 11 (2015): 183-190. https://doi.org/10.14257/astl.2015.99.06

[5] Moors, Janneke, Lisa Scholten, Jan Peter van der Hoek, and Jurjen den Besten. "Automated leak localization performance without detailed demand distribution data." Urban Water Journal 15, no. 2 (2018): 116-123. https://doi.org/10.1080/1573062X.2017.1414272

[6] Adedeji, Kazeem B., Yskandar Hamam, Bolanle Tolulope Abe, and Adnan M. Abu-Mahfouz. "Towards achieving a reliable leakage detection and localization algorithm for application in water piping networks: An overview." IEEE Access 5 (2017): 20272-20285. https://doi.org/10.1109/ACCESS.2017.2752802

[7] Martini, Alberto, Marco Troncossi, and Alessandro Rivola. "Vibroacoustic measurements for detecting water leaks in buried small-diameter plastic pipes." Journal of Pipeline Systems Engineering and Practice 8, no. 4 (2017): 04017022. https://doi.org/10.1061/(ASCE)PS.1949-1204.0000287

[8] Shukla, Harshit, Kalyan R. Piratla, and Sez Atamturktur. "Influence of soil backfill on vibration-based pipeline leakage detection." Journal of Pipeline Systems Engineering and Practice 11, no. 1 (2020): 04019055. https://doi.org/10.1061/(ASCE)PS.1949-1204.0000435

[9] Martini, Alberto, Marco Troncossi, and Alessandro Rivola. "Automatic leak detection in buried plastic pipes of water supply networks by means of vibration measurements." Shock and Vibration 2015 (2015). https://doi.org/10.1155/2015/165304

[10] Yazdekhasti, Sepideh, Kalyan R. Piratla, Sez Atamturktur, and Abdul A. Khan. "Novel vibration-based technique for detecting water pipeline leakage." Structure and Infrastructure Engineering 13, no. 6 (2017): 731-742. https://doi.org/10.1080/15732479.2016.1188318

[11] Yazdekhasti, Sepideh, Kalyan R. Piratla, Sez Atamturktur, and Abdul Khan. "Experimental evaluation of a vibrationbased leak detection technique for water pipelines." Structure and Infrastructure Engineering 14, no. 1 (2018): 46 55. https://doi.org/10.1080/15732479.2017.1327544

[12] El-Zahab, Samer, Eslam Mohammed Abdelkader, and Tarek Zayed. "An accelerometer-based leak detection system." Mechanical Systems and Signal Processing $108 \quad$ (2018): $276-291$. https://doi.org/10.1016/i.ymssp.2018.02.030

[13] Solomon, David, Zeev Efrat, and Baruch Solomon. "System, method, and apparatus for synchronizing sensors for signal detection." U.S. Patent Application 14/722,912, filed December 3, 2015.

[14] Yazdekhasti, Sepideh, Kalyan Ram Piratla, John C. Matthews, Abdul Khan, and Sez Atamturktur. "Optimal selection of acoustic leak detection techniques for water pipelines using multi-criteria decision analysis." Management of Environmental Quality: An International Journal 29, no. 2 (2018): 255-277. https://doi.org/10.1108/MEQ-05-2017$\underline{0043}$

[15] El-Zahab, Samer, and Tarek Zayed. "Leak detection in water distribution networks: an introductory overview." Smart Water 4, no. 1 (2019): 1-23. https://doi.org/10.1186/s40713-019-0017-x

[16] Abdelhafidh, Maroua, Mohamed Fourati, Lamia Chaari Fourati, Adel Ben Mnaouer, and Zid Mokhtar. "Cognitive internet of things for smart water pipeline monitoring system." In 2018 IEEE/ACM 22nd International Symposium 
on Distributed Simulation and Real Time Applications (DS-RT), pp. 1-8. IEEE, 2018. https://doi.org/10.1109/DISTRA.2018.8600999

[17] Lin, Huiwen, Hezhi Lin, Xiaoxuan Fang, Mingkang Wang, and Lianfen Huang. "Intelligent pipeline leak detection and analysis system." In 2020 15th International Conference on Computer Science \& Education (ICCSE), pp. 206-210. IEEE, 2020. https://doi.org/10.1109/ICCSE49874.2020.9201761

[18] Bohorquez, Jessica, Bradley Alexander, Angus R. Simpson, and Martin F. Lambert. "Leak detection and topology identification in pipelines using fluid transients and artificial neural networks." Journal of Water Resources Planning and Management 146, no. 6 (2020): 04020040. https://doi.org/10.1061/(ASCE)WR.1943-5452.0001187

[19] Wu, You, Kristina Kim, Michael Finn Henry, and Kamal Youcef-Toumi. "Design of a leak sensor for operating water pipe systems." In 2017 IEEE/RSJ International Conference on Intelligent Robots and Systems (IROS), pp. 6075-6082. IEEE, 2017. https://doi.org/10.1109/IROS.2017.8206506

[20] Dvajasvie, G., Banu PK Farisha, Sachin N. Babu, K. P. Saheen, and Nikhil C. Binoy. "Leak Detection in WaterDistribution Pipe System." In 2018 Second International Conference on Intelligent Computing and Control Systems (ICICCS), pp. 1-4. IEEE, 2018. https://doi.org/10.1109/ICCONS.2018.8663193

[21] Chatzigeorgiou, Dimitris M., Kamal Youcef-Toumi, Atia E. Khalifa, and Rached Ben-Mansour. "Analysis and design of an in-pipe system for water leak detection." In International Design Engineering Technical Conferences and Computers and Information in Engineering Conference, vol. 54822, pp. 1007-1016. 2011. https://doi.org/10.1115/DETC2011-48395

[22] Bai, Chi-Jeng, Yang-You Lin, San-Yih Lin, and Wei-Cheng Wang. "Computational fluid dynamics analysis of the vertical axis wind turbine blade with tubercle leading edge." Journal of Renewable and Sustainable Energy 7, no. 3 (2015): 033124. https://doi.org/10.1063/1.4922192

[23] Joung, Tae-Hwan, Hyeung-Sik Choi, Sang-Ki Jung, Karl Sammut, and Fangpo He. "Verification of CFD analysis methods for predicting the drag force and thrust power of an underwater disk robot." International Journal of Naval Architecture and Ocean Engineering 6, no. 2 (2014): 269-281. https://doi.org/10.2478/IJNAOE-2013-0178

[24] Inc., ANSYS. "Modeling Turbulent Flows." Prof Neil W. Bressloff nwb Lectures. University of Southampton, June 29, 2018. https://www.southampton.ac.uk/ nwb/lectures/GoodPracticeCFD/Articles/Turbulence Notes Fluentv6.3.06.pdf 